\title{
Protección penal del Emperador. El caso de Tiberio
}

\author{
Emperor's criminal protection. The case of Tiberius
}

\author{
Juan Pérez Carrandi* \\ Real Centro Universitario Escorial - María Cristina \\ Universidad Villanueva \\ Madrid, España
}

\begin{abstract}
RESUMEN: El primitivo Derecho penal romano calificó como delitos desde una etapa muy temprana los atentados a la comunidad, y en el último tercio republicano, con el expansionismo romano las formas de materializar la defección al Estado se actualizaron, surgiendo la noción de crimen contra la majestad de Roma. Sin embargo, la llegada del Imperio implicó modificaciones profundas en la noción de majestad, pasando ésta a referirse de forma gradual a la figura del emperador como bien jurídico protegible en tanto que este era cabeza del Estado. Fue bajo Tiberio cuando se llevó a cabo el grueso de esta profunda transformación penal.
\end{abstract}

PALABRAS CLAVE: Derecho penal; Principado; Tiberio.

ABSTRACT: The Early Roman criminal law, at a very stage, qualified as crimes committed against the community, and in the third republic, with Roman expansion, materialized as defection to the State; such emerged the notion of crimen against the "majesty" of Rome. However, the arrival of the Empire implied profound modifications in the notion of "majesty", gradually coming to refer to an emperor figure as a protected legal good given that the emperor represent the head of the State. It was under Tiberius that this profound criminal transformation took place.

KEYWORDS: Criminal Law; Principality; Tiberius.

\section{INTRODUCCIÓN}

El deseo de llevar a cabo un estudio del Derecho público imperial, a través de su vertiente penal, nos lleva a la etapa del emperador Tiberio quien, por medio de las modificaciones que en materia legal dispuso, marca un hito dentro del desarrollo del ordenamiento jurídico en el ámbito público, si bien será la introducción de concretas normativas en materia penal el más expresivo punto de inflexión hacia una política de intervencionismo imperial dentro del Derecho público. En este sentido, el Princeps desarrolla una política de reformismo judicial intervencionista con dos claros objetivos, de un parte implementa la legislación vigente para, paulatinamente, promover la protección jurídica de su persona, esto es, de la institución imperial personificada, y trabaja contemporáneamente para hacer del nuevo órgano de poder una jurisdicción preferente en la cognición de diferentes causas civiles y

\footnotetext{
* Doctor en Derecho por la Universidad Complutense de Madrid. Profesor Asociado en Real Centro Universitario María Cristina y Centro Universitario Villanueva. Madrid. España. Correo electrónico: jcarrandi@rcumariacristina.com
} 
penales. De esta forma, Tiberio trata de situar al Derecho como protector de su figura pero también persigue que aquél esté controlado por la cúspide del nuevo régimen, ambos objetivos desarrollados de manera paulatina. Eso sí, antes de abordar esta tarea es fundamental realizar un breve recorrido dentro de la evolución que vive la justicia penal hasta el inicio del Principado y luego detenerse en el seguimiento de un crimen que será empleado por el poder imperial -iniciándose tal práctica bajo la voluntad enérgica de Tiberio- como una herramienta de represión política, hablo del delito de atentado contra la comunidad, que tiene remotos orígenes y un específico bien jurídico protegible, el Estado romano en su conjunto y su estabilidad y seguridad. Por ello, desde el mismo inicio de la civitas, quien pusiese en peligro -o cuestión- alguno de estos aspectos es acusado de traidor y eliminado. Sin embargo, Tiberio pervertirá deliberadamente el objeto de protección del delito, que pasa a estar representado por la propia persona del emperador, al ser este máximo representante del Estado. Dicha "mutación" legal es objeto de análisis a través del estudio de obras de Tácito, Suetonio y Casio.

\section{INICIOS Y DESARROLLO DEL DERECHO PENAL}

En origen la comunidad solo interviene para reprimir criminalmente comportamientos antisociales cuando por medio de estos se ve comprometida la pax deorum, esto es, el estado de convivencia existente entre humanos y dioses, y es el rey durante la Monarquía el encargado de juzgar y castigar a tales individuos en calidad de máximo representante de la civitas frente al panteón de dioses. En este sentido las leges regiae se erigen por entonces como el cuerpo normativo más antiguo en Roma y sirven de sustento legal a la regulación de la referida pax deorum ${ }^{1}$. Las leges, aun conteniendo un importante valor religioso, no impidieron que de manera progresiva el Estado se fuese interesando por los ilícitos domésticos surgidos dentro de las relaciones de familia y vecindad, por lo que se pasa de un ejercicio privado e incontrolado de la represalia a una creciente intervención pública a través del establecimiento de expiaciones punitivas ${ }^{2}$. Otros delitos que afectan a la esfera pública, caso de la deserción, defección, cobardía, sedición, relacionados todos en buena medida con el mundo militar, si bien no alteran la pax deorum, producen un daño al conjunto de la civitas romana, siendo así castigados por medio de la potestad del Rey ${ }^{3}$.

Con el advenimiento de la República todos los poderes que venía concentrando el monarca se redistribuyen en diferentes magistraturas que tenderán a ser colegiadas y con una función limitada en el tiempo a través de la elección. El Senado y las asambleas populares también adquieren protagonismo. En el ámbito penal surgen tribunales compuestos de un jurado de

\footnotetext{
${ }^{1}$ SantaluCia (1990) p. 27.

${ }^{2}$ SANTAlucia (1990) p. 30 señala que algunas infracciones más leves (scelus expiables) conllevarán la obligada realización por parte del infractor de ofrendas expiatorias (piaculum), si bien determinados delitos considerados de mayor gravedad comportarán que el transgresor deba responder con su persona o sus bienes ante la divinidad. La violencia ejercida contra un padre, la practicada por la nuera sobre su suegro, el movimiento de lindes con el arado, etc., son delitos que requerirán la consecratio del delincuente, es decir, su expulsión de la comunidad para ser ofrecido a los dioses mediante la ejecución ritualizada.

3 SANTAlucia (1990) p. 34 expone que el monarca se ayudará en las labores de procesamiento de diferentes funcionarios: los quaestores parricidi, por ejemplo, se encargarán de vigilar la ejecución de la venganza ante el pueblo (in contione) y los duumviri perduellionis se erigirán como un tribunal especial encargado de procesar sumariamente a los acusados de traición (reo perduellis).
} 
extracción popular (iudicia populi). El pueblo reunido en asamblea juzga las causas criminales. Se sabe que a inicios de la República se restringe el número de delitos que conllevan la pena capital, se trata del furtum, la iniuria, la perduellio, etc. Ha de reconocerse la escasez de fuentes que en el ámbito del Derecho encontramos, no solo en la propia Monarquía sino en la misma etapa republicana y hasta inicios del s. III a.C., momento en el que la sociedad romana sufre importantes cambios a raíz de la Segunda Guerra Púnica (218-202 a.C.). El escenario que deja el conflicto armando convierte en obsoleto el sistema procesal empleado en los iudicia populi. Enfrentado a delitos de especial gravedad, el Senado decreta la creación de tribunales especiales que irán recepcionando grupos delictivos en cada nueva corte, surgiendo así audiencias provisionales y especiales, las quaestiones repetundae. La primera de estas es la quaestio de repetundis, que perseguirá una nueva forma delictiva que nace al compás de la expansión imperial, el crimen repetundarum, ilícito que implicaba la actividad fraudulenta de los cargos políticos romanos durante su período de gobierno provincial. En adelante surgirán otros tribunales especiales, primero de carácter temporal pero luego permanentes, hablo de la questio de ambitu, quaestio de maiestate, quaestio de veneficiis, entre otras. En la etapa de Sila se reorganizan las quaestiones, siendo dividido el cuerpo de senadores en diez curias de sesenta miembros cada una, y de esta forma en cada proceso se elegían a sesenta patres por acuerdo o recusación de las partes. En adelante aparecerán nuevas quaestiones: la questio de parricidiis, bajo Pompeyo, o la quaestio de vi, bajo César.

\section{DELITO DE MAIESTAS}

Del concepto de maiestas dice MoMMSEN que designaría una actitud de respeto de los súbditos ante un ente superior y, más concretamente, en el ámbito penal el término se acuñaría para proteger a los más antiguos representantes de la plebe a través de la figura del tribuno ${ }^{4}$. Este pasaría a estar protegido por la maiestas populi Romani, la cual protegería no solo a la plebe en conjunto sino también a la falta de reverentia o respeto a la sociedad romana en general. En sintonía con Mommsen, KUNKEL se refiere a la maiestas como a la soberanía, esto es, estar en la posición más elevada, por lo que el delito de maiestas no será otro que el atentado a la soberanía ${ }^{5}$. BAUMAN incide en la fuerte peculiaridad que vive el concepto, que derivaría de maior, no siendo la intención expresar un valor absoluto sino una relación desigual entre dos componentes, maior y minor ${ }^{6}$. En este rol de poderes la maiestas simbolizará para Bauman la superioridad de Roma respecto al resto de pueblos. Dando un paso más, SBRICCOLI ${ }^{7}$ cree que el término se inserta en un campo doctrinal extenso al encontrarnos ante un concepto que puede presentar varios significados. El

4 MommSEn (1991) pp. 341-342 (expresa este autor que estos cargos no ostentarían aún el grado de magistratura y por ello los que atentasen contra su persona o actividad política no se les podría acusar de perduellio -antiguo delito de traición en los primeros siglos de la historia de Roma- al no tener por entonces los plebiscitos carácter de lex publica. De esta forma, la plebe solicitará el mismo nivel de protección para sus representantes que el otorgado a la comunidad en su conjunto y su alto cuerpo de magistraturas).

${ }^{5}$ KunKel (2012) p. 80.

${ }^{6}$ BAUMAN (1970) p. 2 habla de una relación entre maior y minor y cree que la confusión que gira en torno al concepto nace del error de querer relacionar la maiestas más a una cualidad concreta en un individuo o colectivo en vez de, más acertadamente, centrarse en una relación donde una parte es maior y otra minor.

${ }^{7}$ SBRicCOLI (1974) pp. 185-187. 
vocablo es analizable desde un punto de vista ideológico, jurídico, moral, religioso o linguíístico. Sin embargo, el italiano afirma que en su relación con el poder la maiestas se convertirá en una herramienta dentro de la represión a los atentados contra el Estado. Quiero terminar este breve estado de la cuestión recogiendo las palabras concluyentes de CICERÓN: maiestas est amplitudo ac dignitas civitatis $^{8}$, y para DE CASTRO-CAMERO bajo la idea de maiestas se encuentra una noción de enorme calado para los romanos: su eternidad, expresada por encima de las singulares personas que componen Roma. Dicha idea cimienta la fuerte convicción de superioridad del pueblo romano con respecto al resto 9 .

El delito de maiestas aparece a finales del s. II a.C., imperando hasta entonces el delito de perduellio como el encargado de recepcionar las causas por traición sobre la comunidad ${ }^{10}$. MOMMSEN refiere que la perduellio es tan antigua como la propia comunidad, equivaliendo a la protección del pueblo romano frente a las acciones enemigas ${ }^{11}$. La romanística más contemporánea sostiene de la mano de CANTARELLA que este delito no debió estar expresado específicamente en la legislación romana, sino que, una vez identificada su comisión, se castigaba con la pena capital ${ }^{12}$.

Respecto a la constitución de un tribunal específicamente orientado a la maiestas, hace tiempo se afirmó que la quaestio Apuleya ${ }^{13}$, tradicionalmente referida como primera corte

${ }^{8}$ CICERÓN (1892) p. 164 (de orat, 30.105).

${ }^{9}$ De CASTRO-CAMero (2002) pp. $25-27$

${ }^{10}$ Mommsen (1991) p. 347 no establece una clara distinción entre perduellio y maiestas, limitándose a afirmar que ambos constituyen delitos contra el Estado. De esta forma, habla de un grupo de ilícitos que englobarían al primero y a la segunda: connivencia con el enemigo, atentar contra el orden constitucional romano, violaciones de los magistrados y sacerdotes en sus obligaciones, abandono ciudadano de en sus deberes políticos, ofensas civiles a los funcionarios públicos. BAUMAN (1970) p. 27 cree que perduellio y maiestas se enredan cual madeja, afirmando que las causas capitales llevadas ante los comicios populares debieron ser por perduellio.

${ }_{11}^{11}$ Mommsen (1991) p. 42.

${ }^{12}$ CANTARElla (1996) pp. 146-147 (este autor dice que serán la casuística, los períodos históricos y, ante todo, el clima político reinante en cada momento, los principales factores que harán predominar en algunas etapas la decapitación de los traidores como forma de ejecución, y en otras, en cambio, el empleo de la fustigación o de la defenestración. La provocatio ad populum funcionaría excepcionalmente en dichos contextos durante la Monarquía, y será ya bien entrada la República cuando se establezca como un recurso procesal permanente de todo reo ciudadano romano condenado a pena de muerte. Por otra parte, también a lo largo del período republicano las ejecuciones tenderán a disminuir drásticamente al tiempo que se generaliza el empleo del ius exilli como vía establecida para evitar la ejecución).

${ }^{13}$ MAS (2011) p. 85 opina que el tribuno L. Apuleyo Saturnino, en el 103 o 100 a.C. -fue tribuno en ambas fechas- desarrolló la tipificación de la maiestas como delito con el fin de proteger su programa de reformas, ello dentro del ambiente político popularis reinante a finales del s. II a.C., teniendo además en mente los violentos resultados de políticas similares desarrolladas en los años previos (reformas gracanas), y en este contexto entiende MAS la introducción del crimen maiestatis como un intento de blindar la actividad legislativa de las asambleas populares frente al poder del Senado, contrario este último a las políticas popularis, quien desde entonces atentase contra el tribuno de la plebe, protegido desde muy antiguo por la sacrosanctitas tribunicia, incurría ahora también en un delito de maiestas al ser aquél un representante del populus cuya maiestas estaba expresada en las asambleas populares y sus representantes. 
de maiestas, tendrá un carácter transitorio, y Sila, dentro de su amplia reforma de los tribunales públicos, creó una verdadera quaestio de maiestate, de carácter permanente ${ }^{14}$.

\section{EL NUEVO DERECHO IMPERIAL}

La República romana entra en su último siglo instalada en una crisis social y política creciente $^{15}$ que culmina con la llegada de un nuevo orden político, el Principado, donde los cambios introducidos son muy profundos en diferentes aspectos de la vida pública y, específicamente, en el ámbito del Derecho ${ }^{16}$. En cambio, la transformación es gradual, pues Augusto no olvida el estrepitoso fracaso de César en su intento de forzar un cambio de régimen abruptamente. Precisamente, la primera intervención imperial en la esfera judicial se produce a través del Derecho penal mediante la creación de una jurisdicción especial sustentada en un cuerpo funcionarial propio. Augusto va acaparando las diferentes magistraturas en forma vitalicia pero respeta la autoridad del Senado. A su muerte es deificado.

Si Cicerón identificó la maiestas con la grandeza y dignidad del pueblo romano, en el paso de la República al Principado el concepto modifica su polo de atracción de la maiestas populi Romani a la maiestas Principis. De esta forma, si en la etapa republicana incurría en crimen maiestatis quien atenta contra el Estado romano, con la llegada del Imperio, Augusto tímidamente, y Tiberio más abiertamente, van enfocando el bien jurídico protegible hacia la propia persona del emperador. Salvador MAS ve en la etapa de César un

\footnotetext{
${ }^{14}$ KUNKel (2012) p. 80 manifiesta que en el ámbito de la amplia reforma constitucional, Sila reorganizará y ampliará los tribunales permanentes (quaestiones perpetuae) surgidos para juzgar casos penales que la justicia ordinaria no podía resolver, y que ya estaban operativos desde finales del s. II a.C. Aparecen ahora tribunales para combatir delitos de traición y desobediencia a los órganos estatales, entre otros.

${ }^{15}$ LÓPEZ BARJA y LOMAS SALMONTE (2004) pp. 176-180 creen que el problema real en el período es una mera lucha por el poder y estiman que la visión de una oligarquía republicana muy cerrada no sería del todo acertada, y por tanto, no sería un factor de peso a la hora de explicar un estallido ante el monopolio de una pequeña élite en el ejercicio del poder. Así todo, como recuerda Kunkel, las fuertes fricciones existentes acaban minando el poder del Senado para terminar así favoreciendo la restauración de la Monarquía en la persona de Octavio César Augusto. Los sendos intentos de reforma social emprendidos por los Graco en el último tercio del s. II a.C. desencadenaron los conflictos que llevaron a la debacle final. Las clases dirigentes a través del partido optimate se opusieron a las reformas y, a su vez, la plebe, representada por los populares, hizo resistencia. KUNKEL (2012) p. 60 sostiene que no existirá una específica lucha de clases sino un conflicto dentro de la propia clase aristocrática. Incidiendo en los aspectos económicos y sociales, Pinna Polo señala como el campo italiano fue sufriendo de manera creciente desde el s. II a.C. el surgimiento de medianas y grandes explotaciones agrarias, escenario en el que la mano de obra esclava irá sustituyendo de manera mayoritaria a la libre en los trabajos dentro de las explotaciones, lo que favorece la emigración masiva de itálicos a Roma, lo cual incrementa el proletariado urbano, que va adquiriendo mayor peso político canalizando sus aspiraciones a través del partido popular. Al mismo tiempo, los más pudientes reclaman un mayor peso en las magistraturas, de tal forma que, dice PINNA POLO (1998) pp. 113-114, "el conflicto planteado entre estos advenedizos por lograr el acceso al poder y una parte importante de la élite tradicional por limitarlo o impedirlo, representa una de las claves para entender los problemas políticos del período", una reflexión que nos vuelve a acercar a la idea de lucha de clases.

${ }^{16}$ En este sentido vid. TUORI (2016) pues trata de configurar un estado de la cuestión respecto del Derecho imperial con un trabajo que principia en la etapa de Julio César, la dictadura, y culmina en el primer tercio del s. III, bajo los Antoninos, y combinando fuentes antiguas y romanística actual intenta plantear una visión renovada de los aspectos jurídicos de este amplio período histórico.
} 
punto de inflexión cuando este decide asociar la dignitas Caesaris con la dignitas rei publicae, estrategia continuada, más sutilmente, por Augusto con el fin de construir la maiestas Principis. Todo este proceso se enmarca dentro de "una progresiva sustantivación del Estado en la figura del Princeps: cuando el emperador actúa, actúa la nación; cuando el emperador juzga, juzga el pueblo",17.

\section{CRIMEN MAIESTATIS BAJO TIBERIO A TRAVÉS DE LAS FUENTES CLÁSICAS}

Con Tiberio se consolida el régimen imperial, un período de gobierno que puede ser calificado positivamente, pues en él la gestión económica y administrativa tendió a la contención, aunque respecto a las relaciones con el Senado la experiencia fue mejorable. A nivel militar, la tendencia fue de una progresiva pacificación y no agresión en el ámbito exterior $^{18}$. En palabras de SHOTTER, la eficiente labor de Tiberio en el gobierno imperial no supuso sino la constatación de una seria posibilidad de supervivencia de la institución a la muerte de su fundador ${ }^{19}$.

Posicionando como eje el análisis del delito de maiestas bajo Tiberio, hay que adentrarse en el período a través de la lectura y estudio de los escritos de Tácito, Suetonio y Casio, examinando cada autor respetando las respectivas cronologías en su actividad.

En su obra Annales TÁCITO da cuenta extensamente de la etapa de Tiberio, y lo hace en los libros I al VI, donde ofrece una imagen muy negativa del emperador, al que define como una persona esencialmente cruel, aun estando entrado en años ${ }^{20}$. Totaliza el transcurso de la narración el crimen maiestatis el cual lo emplea con profusión Tiberio para mantener su autoridad absoluta, costumbre que, en adelante, siguen los sucesores en el trono imperial ${ }^{21}$. Este hecho muestra el grado en que la institución imperial transforma en una herramienta de represión política el delito de maiestas pues con anterioridad a las modificaciones de Tiberio se utilizó para perseguir la defección militar, los movimientos sediciosos en el pueblo, o la mala praxis en el desempeño de la función pública: si quis proditione exercitum aut plebem seditionibus, denique male gesta re publica maiestatem populi Romani minuisset, facta arguebantur, dicta impune erant ${ }^{22}$.

Augusto, antecesor de Tiberio, había actuado tímidamente en favor del cambio al procesar a ciertos libelos bajo la acusación de lesión a la maiestas de algunos personajes ilustres de la sociedad romana del momento ${ }^{23}$ y bajo Tiberio se inician los procesos por maiestas

\footnotetext{
${ }^{17}$ MAS (2011) p. 84.

${ }^{18}$ Para saber más del período tiberino vid. Le GALl y LE GlAy (1987) pp. 126-127, SÁNCHEZ LEÓN (1998) pp. 38-39, SHOTTER (2002) pp. 79-104 y BlÁZQUEZ MARTíneZ (2004) p. 44.

${ }^{19}$ SHOTTER (2002) p. 104.

${ }^{20}$ TÁCITO (1965) pp. 184-85 (An, 1.4): Tiberium Neronem maturum annis (...) multaque indicia saevitiae.

${ }^{21}$ TÁCITO (1965) p. $273(A n, 1.72)$.

22 Ibíd.

${ }^{23}$ TÁcito (1965) p. 281 (An, 1.77) expone que parece muy probable que Augusto iniciase el camino de la transformación penal del delito de maiestas, dedicándose únicamente su sucesor a darle curso, idea que se ve reforzada por otras decisiones de Tiberio en materia penal que muestran un continuismo con la doctrina augusta, y así ocurre en el 15 a.C. pues, tras la supuesta incitación al desorden por algunos actores, fallecieron
} 
asociados a la protección penal del emperador: el pretor de Bitinia Granio Marcelo es acusado por el cuestor Cepión Crispino tras haber atentado contra la maiestas del príncipe, si bien Cepión se limitaría a poner en boca del acusado verdades en torno a vergonzosas costumbres de Tiberio $^{24}$. Un tal Romano Hispón apoyaba el encausamiento ampliando la acusación: el reo de maiestas había erigido una estatua de mayor altura que las imperiales y, además, había decapitado una efigie de Augusto para colocar el busto de Tiberio ${ }^{25}$. Las acusaciones y la declaración de Marcelo se formalizaron en el Senado y, a continuación, el emperador solicitó formar parte del tribunal y emitir su voto, ello porque el órgano encargado de conocer de las causas por maiestas era el propio consejo de ancianos a través de un grupo de estos constituido en una corte permanente que deliberaría las causas a través de mayoría de voto. Pero los deseos de Tiberio se vieron truncados por la demoledora y oportuna intervención del senador Gneo Pisón, hostil a tal posibilidad, quien preguntó al emperador en qué momento del proceso emitiría su juicio, al tiempo que ironizaba ante el temor de disentir en una u otra ocasión del parecer de Tiberio ${ }^{26}$. Es indudable que Pisón estaba denunciando abiertamente la intromisión del emperador en una causa judicial cuya resolución únicamente correspondía al Senado, y en esa ocasión, tras el disentimiento, el reo fue absuelto (absolvi reum criminibus maiestatis) ${ }^{27}$. Tiberio acudió al proceso movido por lo que habría considerado un atentado contra su imagen y la del propio Augusto, ambas dignidades imperiales, pues se habría producido un menoscabo de la institución. Sin embargo, ante la protesta del Senado a raíz de su intromisión, Tiberio decidió desistir y ello favoreció la absolución, mas la tendencia del emperador a hacerse notar en los tribunales será creciente y no estará limitada a las causas públicas porque decide acudir a juicios civiles ocupando un espacio en el tribunal llegando a hacer sombra al pretor en su $\operatorname{actividad}^{28}$.

Una causa en que se acusa conspiración es igualmente buen ejemplo del proceso de descomposición que comienza a producirse dentro de las filas senatoriales como órgano autónomo, en concreto, el senador Firmio Cato ha ido introduciendo a su gran amigo Libón Druso, de la familia de los Escribonios, en el mundo del ocultismo y la superchería y no deja de recordarle sus nobles orígenes y el grado de ambición al que había de optar pero en un momento, sorpresivamente, resuelve comunicar al propio César las peligrosas intenciones que tendría el joven Libón sobre su persona ${ }^{29}$. Por entonces la superchería y las artes adivinatorias estaban prohibidas en Roma, y la denuncia de Firmio Cato se entendió como la delación de una actividad ocultista y conspirativa contra la figura imperial, cuando

varios ciudadanos y algunos militares, un centurión y un pretor pretoriano resultaron heridos, y el Senado propuso apalear al gremio de actores pero se negó rotundamente Tiberio refiriendo que el divino Augusto les concedió un rango de protección especial y no le estaba a él permitido contravenir sus palabras.

${ }^{24}$ TÁCITO (1965) p. 277 (An, 1.74.3): moribus principis...

${ }^{25}$ TÁCITO (1965) p. 277 (An, 1.74.4): statuam altius quam Caesarum sitam, et alia in statua amputato capite Augusti effigiem Tiberii inditam.

${ }^{26}$ TÁcITo (1965) p. 278 (An, 1.74.6): ‘quo’inquit `loco censebis, Caesar? si primus habebo quod sequar: si post omnes, vereor ne imprudens dissentiam'.

${ }^{27}$ TÁcITO (1965) p. 278 (An, 1.74.6).

${ }^{28}$ TÁcITO (1965) p. 278 (An, 1.75.1): ...ne praetorem curuli depelleret.

${ }^{29}$ TÁcito (1965) p. 318 (An, 2.28). 
en verdad se estaba ante un acto de ruindad de parte de un senador ${ }^{30}$ que además actuó como delator, una figura fundamental para entender en adelante el juego procesal que se le da a un crimen maiestatis que está en un momento de plena transformación. Con todo, Tiberio aún no decide participar de la instrucción y resolución de estas causas pues, ante la denuncia de Firmio, deriva el conocimiento de los hechos al caballero Flaco Vesculario. Finalmente, Fulcinio Trión, famoso delator, acude ante los cónsules para solicitar que el Senado abra un procedimiento al respecto (cognitionem senatum poscit) ${ }^{31}$. Puede afirmarse que Fulcinio Trión emprendió la vía procesal correcta, dando noticia a los cónsules para que estos solicitasen luego al Senado -a través de la quaestio correspondiente- abrir diligencias y Firmio Cato, al pretender acudir directamente ante Tiberio con idéntico objetivo, habría pervertido los causes procesales. Esto último muy probablemente llevó al emperador a entregar el asunto a un caballero de su confianza. Ya en juicio, el emperador sí decide enumerar ante el reo los cargos que se le imputan y los testigos que los corroboran, si bien en forma comedida porque hablaba midiendo sus palabras de manera que no pareciese que aminoraba o agravaba las acusaciones ${ }^{32}$. La presencia de Tiberio en el tribunal no está clara, en principio, hay que entender su carácter plenamente prescindible pues no cumple función alguna de acuerdo con el Derecho público del momento y con la concreta praxis procesal referida a las quaestiones y, más allá de esto, hay que valorar la presencia del emperador como un primer acercamiento a la actividad de la corte dentro de una labor de progresiva intromisión en la actividad judicial. De esta forma, el papel de Tiberio, secundario, limitándose a enumerar los cargos del reo, se inserta dentro de esa estrategia de influencia paulatina y, además, su actitud en el momento de la exposición pública, temerosa de derivar en un pronunciamiento de parte, ahonda más en dicha línea.

En el momento de escuchar la acusación hubo conflicto ya que junto a Trión aparecieron otros dos acusadores, Cato Fonteyo Agripa y Gayo Vibio ${ }^{33}$, este último comenzó afirmando que Libón había escrito en cierto libelo expresiones espantosas en torno a la figura de distinguidos senadores, incluso sobre el propio César, negando el acusado tal extremo, y se hizo necesario interrogar a los esclavos de Libón que Trión había llevado como prueba a juicio, lo que planteaba serios problemas procesales pues los esclavos solo podían declarar bajo tortura $^{34}$. Aquí el emperador ejecuta la primera modificación del orden legal vigente,

30 RoldÁn Hervás (2008) p. 207 explicó tan deplorable comportamiento insertándolo en el desolador contexto reinante en el ámbito senatorial en el período; si en época de Augusto su poder y autonomía se vio alterado, la situación empeorará con la llegada de Tiberio, una etapa donde la promoción a través del servicio al Estado era el elemento dinamizador, pero ahora, siendo el emperador el propio dispensador de dicha promoción con arreglo a su mera voluntad, los méritos para escalar estaban cambiando: "Fue infundiéndose un nuevo comportamiento aristocrático en el que, para obtener el favor imperial, no se dudaba en recurrir a comportamientos odiosos y rastreros, basados en la adulación, el servilismo, la intriga y las denuncias recíprocas".

31 TÁCITO (1965) p. $314(A n, 2.25)$.

32 TÁCITO (1965) p. $318(A n, 2.29)$.

33 TÁCITO (1965) p. 319 (An, 2.30) señala que surgió entre éstos la discusión en torno a quien debía tomar la palabra en primer lugar y, finalmente, se elegirá a Vibio.

${ }^{34}$ En relación a la prueba testifical a través de esclavos DE CASTRO-CAMERO (2002) p. 167 recuerda que los testimonios de estos se producían a continuación de los prestados por los hombres libres, con o sin ciudadanía romana (el testimonio de mujeres y menores, si bien era practicado, tenía menor valor). Los esclavos solo eran interrogados en casos de gran necesidad, pues por norma, sus testimonios carecían de la más mínima confianza. 
introduciendo un nuevo derecho al respecto (novi iuris repertor) ${ }^{35}$, ordena vender los esclavos al fiscus (la hacienda imperial), propiedad del emperador, y a raíz del cambio se salvaba la prohibición de los esclavos de declarar contra su dominus. El clima era ya abiertamente desfavorable al reo en ese tribunal, por lo que Libón pide un aplazamiento de la sesión que le es concedido, marcha a su domicilio y, en adelante, queda bajo custodia de guardias armados -custodia militaris- a modo de encarcelamiento preventivo ${ }^{36}$. Es probable que sea este el primer caso documentado de arresto del reo dentro del Derecho romano, afección de libertad que en todo caso duró poco porque el reo se suicidó. El Derecho establece la extinción de la causa si muere el acusado antes del fallo judicial pero en este caso Tiberio muestra un fuerte interés en que el proceso siga, y así ocurre resultando el difunto culpable y siendo embargados todos sus bienes, los que se reparten entre los acusadores (delatores). La lex Iulia de maiestate referida en el Digesto menciona la posibilidad de continuar el proceso en una causa por maiestas pese a haber muerto el reo, y muy probablemente esta innovación legal y la compra de esclavo del acusado para poder dar validez al testimonio de aquél son introducciones normativas pertenecientes a la etapa de Tiberio y, más concretamente, resultado del curso de este proceso.

El embargo de bienes del difunto, que pasan a manos de la acusación, se convirtió en un precedente extraordinariamente aliciente para futuras acusaciones por maiestas, Tiberio por medio de la puesta en práctica de este tipo de medidas creó un clima favorable a la actividad de los delatores y logró la proliferación de acusaciones sobre reus maiestatis, su política favoreció acusaciones al interior de la familia imperial, Apuleya Varila, nieta de Octaviana -hermana de Augusto- a través de un delator fue acusada de pronunciar palabras injuriosas sobre Augusto, Tiberio, y su madre, y también mantener actitudes adúlteras a la vez que era pariente del César ${ }^{37}$. Como pena de fondo aparece en ambos casos el atentado contra la imagen de la familia imperial pero en esta ocasión Tiberio pidió que se juzgue a Varila solo por los ataques sobre Augusto y bajo ningún concepto en cuanto a él y su madre atañese. La actitud de Tiberio es astuta porque comienza a favorecer la creación de procesos por maiestas a través de una serie de medidas y se reserva la inmediata protección que el delito otorga a su propia persona decidiendo enfocar esa cobertura penal sobre la persona imperial de Augusto, siendo cuestión de tiempo que termine blindando su propia figura a través de este crimen.

Bajo Tiberio tuvo lugar el juicio relacionado con la muerte de Julio César Germánico en el 19 d.C. Cneo Calpurnio Pisón fue acusado por Fulcinio Trión de estar detrás de ese deceso mediante envenenamiento, y fue también acusado de incitar el levantamiento de los cuarteles de Germania a la muerte de Augusto y, más grave aún, conspirar contra el Estado romano. Vitelio, Veranio y otros amigos de Germánico acudieron al juicio como testigos y delatores del difunto ${ }^{38}$ y a Pisón se asociaron defensores como Manio Lépido, Lucio Pisón o Livineyo Régulo. Trión, en calidad de delator, pidió a Tiberio presidir la quaestio del

\footnotetext{
35 TÁCITO (1965) p. 319 (An, 2.30).

36 PAVÓN TORREJón (2003) p. 202 dice que parece que este tipo de arresto domiciliario fue aplicado en ocasiones sobre individuos de elevada posición social inmerso en una causa penal.

37 TÁCITO (1965) p. 344 (An, 2.50).

${ }^{38}$ TÁCITO (1965) p. $403(A n, 3.10)$.
} 
Senado y esta corte se mostró implacable, Tiberio, por ser Pisón responsable de una guerra en la provincia a él asignada, Siria, y el Senado, por no haber creído en momento alguno las causas "oficiales" que giraban en torno a la muerte de Germánico ${ }^{39}$. El proceso se aplazó y, en un nuevo ejemplo de militaris custodia, Pisón murió durante la noche pero en esta ocasión no hubo embargo de los bienes del reo tras su suicidio y Tiberio favoreció que se respetara la preceptiva sucesión patrimonial al hijo del acusado 40 .

Otro ejemplo de proceso por crimen maiestatis a través de la realización de superchería en torno a la casa imperial es el de Lépida, bisnieta de Lucio Sila y Gneo Pompeyo, quien habría indagado el futuro de la casa del César empleando astrólogos ${ }^{41}$, acá la acusada fue defendida por su hermano y el emperador solicitó de forma encubierta al cónsul Marco Servilio y a otros supuestos testigos presentar pruebas en favor de la acusación, los esclavos de Lépida fueron interrogados mediante tortura -entiendo que luego de ser incorporados al fiscus imperial- a raíz de lo cual surgieron testimonios incriminatorios, momento en que la acusación pidió la aplicación de la interdicción (aqua atque igni arcebatur) ${ }^{42}$.

El juicio de los delatores y caballeros romanos Considuo Ecuo y Celio Cursor por maiestas causa sorpresa porque ambos son incriminados por el propio Tiberio por realizar una acusación falsa sobre la persona de Magio Ceciliano y la acción del emperador contradice su tendencia de amparo y promoción de los delatores de delitos de maiestas. En este sentido, las acusaciones por maiestas eran tan habituales que Ancario Prisco con ocasión de demandar por concusión a Cesio Gordo, procónsul en Creta, añadió el delito de maiestas pues este era por entonces un complemento perfecto a todas las acusaciones (quod tum omnium accusationum complementum erat). A Antistio Vetere, uno de los próceres de Macedonia, una vez absuelto de la acusación de adulterio, lo que motivó que el emperador reprendiera a los jueces (increpitis iudicibus), Tiberio lo acusó de maiestas (ad dicendam maiestatis causam retraxit) ${ }^{43}$ siendo el resultado final una condena al exilio. Los juicios por maiestas desarrollan, en los casos en que hay condena, un procedimiento que -recoge Manio Lépido- comprende la interdicción, el exilio y el embargo de bienes: cedat tamen urbe et bonis amissis aqua et igni arceatur; quod perinde censeo ac si lege maiestatis teneretur ${ }^{44}$.

\footnotetext{
${ }^{39}$ TÁCITO (1965) p. 408 (An, 3.14).

40 TÁCITO (1965) p. $411(A n, 3.17)$.

${ }^{41}$ TÁ́CITO (1965) pp. 416-417 (An, 3.22).

${ }^{42} 42$ TÁcito (1965) p. 419 (An, 3.23.3). Ribas Alba y SERrano Vicente (2012) p. 107 recuerdan que originariamente este tipo de pena, que no es otra que la de exilio (ius exilii), estaba relacionado con el ius Latii, implicando la posibilidad de modificar la ciudadanía romana a través del cambio forzoso de domicilio (ius civitatis mutandae). Con la llegada de la interdicción del agua y el fuego, luego de decretar la supresión de ciudadanía del reo, la pena de muerte es sustituida por el exilio a una ciudad con la que Roma tuviese firmado un convenio en tal sentido.

${ }^{43}$ TÁCITO (1965) p. 438 (An, 3.38.2).

44 TÁCITO (1965) p. $451(A n, 3.50 .6)$.

TÁciTo (1965) pp. 451-452 (An, 3.51) manifiesta que las palabras de Manio Lépido se contextualizan durante el proceso al caballero romano Clutorio Prisco, acusado de componer un poema sobre el difunto Germánico. Lépido sacará a colación la pena prevista para los casos de maiestas intentando que esta le sea aplicada a Prisco, si bien con nulo resultado, pues este será encarcelado y luego ejecutado tras ser encontrado culpable.
} 
Gayo Silano, procónsul en África, fue enjuiciado por concusión, por ultrajar la divinidad de Augusto y despreciar la maiestas de Tiberio ${ }^{45}$, la acusación, colectiva, estuvo compuesta por el ex cónsul Mamerco Escauro, el pretor Junio Otón y el edil Brutedio Níger, y no hay que pensar aquí en una labor altruista de los delatores, quienes -he dicho al respecto- ven en su conducta una manera más efectiva de lograr un ascenso político. En la causa es muy significativa la postura del emperador pues su papel es activo, personalmente interroga al reo en un tono que pierde la neutralidad teatralizada en el pasado, presiona las declaraciones con palabras y gestos hasta el punto de forzar al temeroso Gayo Silano a pronunciarse en contra de la verdad por temor a resaltar la impertinencia de la pregunta ${ }^{46}$. Nuevamente, los esclavos del acusado son comprados por la casa imperial para ser interrogados bajo tortura ${ }^{47}$ y para evitar que amistades de Silano acudan al juicio en su defensa se entablaron contra ellas acusaciones por maiestas, el emperador para cerrar una sentencia pidió el parecer a Lucio Pisón y este se posicionó en favor del exilio y así se dispuso, si bien el emperador matizó que el reo marcharía a Citino, a petición de la hermana del condenado, y su patrimonio no iría a parar al fiscus sino a manos del heredero natural de Silano, su hijo, esto último a petición de Gneo Léntulo, miembro del tribunal ${ }^{48}$.

Habiéndose abierto proceso contra -entre otros- el caballero Lucio Ennio, acusado de maiestas por fundir una estatua de Tiberio para destinar el metal a uso común, el Senado manifestó públicamente que el emperador decida no aplicar la represión al delito de maiestas en la forma prevista -por él mismo- y que se reste capacidad de decisión al consejo de ancianos en relación a la deliberación sobre dicho crimen, finalmente el Tiberio prohibió ser incriminado Ennio (recipi Caesar inter reos vetulit), pero este ejemplo de indulgencia es excepcional, por ejemplo, por manifestarse cómplice con el bando enemigo germano en la guerra romana contra este pueblo, Gayo Silio, quien junto a su mujer fue acusado por maiestas a petición del emperador, se quitó la vida antes de la condena y sus bienes los embargó el físco imperial y pasaron directamente a manos de Tiberio ${ }^{49}$.

Las conversaciones secretas abrieron en el periodo otra posible vía de enjuiciamiento por maiestas $^{50}$, y por tal motivo fue encausado Lucio Pisón, acusado por Quinto Granio, murió por causas naturales durante el proceso y el litigio finalizó, por lo que puede afirmarse que únicamente continuarían los juicios de maiestas post mortem en caso de suicidio del reo. Es de suponer que las conversaciones prohibidas lo son porque giran en torno a la familia imperial o al emperador directamente y ciertamente es un hecho que el delito de maiestas se utilizó para blindar la institución imperial, cuya máxima representación la encarna la

45 TÁcito (1965) p. 470 (An, 3.66.2): corripiunt obiectantque violatum Augusti numen, spretam Tiberii maiestatem.

${ }^{46}$ TÁCITO (1965) p. 472 (An, 3.67.2): non temperante Tiberio quin premeret voce vultu, eo quod ipse creberrime interrogabat, neque refellere aut eludere dabatur, ac saepe etiam confitendum erat ne frustra quaesiuisset.

${ }_{47}^{4}$ TÁCITO (1965) p. 472 (An, 3.67.3): servos (...) actor publicus mancipio acceperat.

${ }^{48}$ TÁcito (1965) p. $472(A n, 3.68)$.

${ }^{49}$ TÁcITo (1965) pp. 513-514 (An, 4.19). TÁcito (1995) pp. 515-516 (An, 4.20.2) dice que será la primera ocasión en que Tiberio se interese por el dinero ajeno (ea prima Tiberio erga pecuniam alienam diligentia fuit).

${ }^{50}$ TÁcITo (1965) p. 516 (An, 4.21.3): secreti sermonis incusauit adversum maiestatem habiti. 
figura del propio príncipe. El caso de Vocieno es el enésimo ejemplo, al ser acusado de maiestas por verter insultos sobre Tiberio, respondiendo el afectado en juicio virulentamente $^{51}$, terminó el reo suicidándose, en fin, el emperador envió al pretor Sexto Vistilio una carta donde le acusó de difamaciones contra el difunto Cayo Julio César y de inmediato aquél emprendió igual final que Vocieno ${ }^{52}$. Tampoco las mujeres escaparon del cargo de maiestas -vid. supra caso de Lépica- y al no poder ser acusadas de atentar contra el Estado se las enjuicia a través de sus lágrimas ${ }^{53}$ (hablaría aquí de lutos inoportunos sobre individuos hostiles a los ojos de Tiberio).

En el tramo final del gobierno de Tiberio la imposición del exilio como pena cayó en el olvido, y casos como el de Considio Próculo, acusado de maiestas e inmediatamente juzgado y ajusticiado, vuelven a ser habituales. En este escenario muchos reos optaron por el suicidio inmediato, porque, pese a serles posteriormente embargados todos los bienes, ya no se les daría sepultura a continuación. ${ }^{54}$

Más brevemente Suetonio se ocupa en de vita Caesarum de la figura de Tiberio, en el libro III, su relato es sencillo y alejado en gran medida de los aspectos políticos como eje de la narración, pero tampoco tiene buenas palabras para el emperador, de quien dice que en su niñez muestra una naturaleza cruel y morbosa (saeva ac lenta natura ne puero quidem latuit $^{55}$, y enumera las atrocidades de Tiberio con gran crudeza con el objetivo de transmitir el carácter indolente del príncipe ${ }^{56}$.

Hay un clima de acoso procesal que comienza a desarrollarse sobre quienes ofendiesen, a través de las formas más variopintas, a la figura del difunto Augusto: Circa Augusti simulacrum servum cecidisse, vestimenta mutasse, nummo vel anulo effigiem impressam latrinae aut lupanari intulisse, dictum ullum factumque eius existimatione aliqua laesisse ${ }^{57}$. La protección penal de la imagen del emperador difunto se va gestando a través de diferentes procedimientos que se abren en tal sentido, y con ello, de una manera muy astuta, Tiberio comienza a proteger la propia institución imperial, el siguiente paso será extender ese nivel de protección a su persona.

Cierto individuo provincial fue condenado a muerte por serle ofrecidos honores en el mismo día en que, años antes, le habían sido otorgados a Augusto ${ }^{58}$. A Lépida se le condenó por la presión que ejerció Tiberio, para agradar al antiguo cónsul Quirino, quien,

51 TÁcito (1965) p. 541 (An, 4.42.3): Caesar obiectam sibi adversus reos inclementiam eo pervicacius amplexus.

52 TÁcITo (1965) p. 606 (An, 6.9.3-4).

${ }^{53}$ TÁ́ciтo (1965) pp. 608-609 (An, 6.11).

${ }^{54}$ TÁ́cito (1965) pp. 630-631 (An, 6.29).

${ }^{55}$ SUETONiO (1964) p. 64 (de vita, 3.57.1).

${ }^{56}$ Por ejemplo, refiere SUETONIO (1964) pp. 58 (de vita, 3.57.2) y 67 (de vita, 3.60) que, respectivamente, a un individuo que durante el paso de un entierro exclamó jocosamente al difunto que anunciase al desaparecido Augusto que aún no se había dado satisfacción a los legados que dicho emperador dispuso para la plebe, Tiberio mandó pagar al ciudadano lo demandado para luego ser llevado a ejecutar, y a un pescador que lo asaltó durante su retiro en Capri mandó desfigurarle el rostro con el mismo pez.

${ }^{57}$ SUETONIO (1964) pp. 65-66 (de vita, 3.58).

${ }^{58}$ SUETONIO (1964) pp. 64-65 (de vita, 3.57). 
habiéndola repudiado veinte años atrás, la acusaba, ahora, de intentar entonces envenenarle $^{59}$, y menciona la prohibición establecida por el emperador sobre consultas adivinatorias secretas y sin testigos sobre su persona ${ }^{60}$ y la promoción de una política de prebendas a los delatores para favorecer su actividad ${ }^{61}$.

CASIO -más cercano a la erudición de Tácito que a la característica inexactitud de Suetonio-, pese a que en su Historiae Romanae la crónica al respecto es escasa, traza con credibilidad y rigor los elementos más característicos del gobierno de Tiberio. El autor censura comportamientos crueles del emperador ${ }^{62}$ y sobre la injerencia de éste en la actividad judicial afirma que el príncipe frecuentaba los tribunales hablando como consejero cuando convenía, actitud que se da solo en el periodo inicial de su gobierno, momento en el que aún mantenía las formas, teniendo luego un interés progresivo por inmiscuirse en dicha actividad, en especial en torno a la desarrollada en los tribunales penales senatoriales, y el cambio se produjo con la llegada de Tiberio a Capri, instante en el que, pese a seguir reuniéndose la asamblea de patres, el emperador se interesó por que ella se constituyese siempre que fuese oportuno, en el tiempo y forma debidos, y comenzó a enviar al Senado instrucciones en estos y otros sentidos, comenzando así el control del funcionamiento de la cámara ${ }^{63}$.

En relación a la maiestas al principio el emperador se muestra pasivo respecto de la represión de un delito y lentamente pasa a blindar jurídicamente su persona y el nuevo régimen en general. En el trascurso de un proceso contra un individuo acusado de vender una estatua de Augusto junto a su domicilio, el cónsul solicitó a Tiberio su parecer y este, temeroso de evidenciar que se favorecía a sí mismo se pronunció en favor de absolver al acusado $^{64}$. Evidencio a través de este ejemplo, una vez más, la política en apariencia renuente del emperador a la hora de adquirir mayor protagonismo en el ámbito judicial y, también, en cuanto a dar un impulso decidido a la conversión de la maiestas en un objeto de protección legal de su persona a través de la institución que encarna, pero esto cambia en el tiempo y en un momento intermedio el emperador, si bien no consiente que le levanten efigies, es inflexible con los que se muestren impiadosos hacia él. Esos ataques al emperador motivaron gran cantidad de causas y si primero fue permisivo con quienes ofendieron a su predecesor Augusto pronto derivó en abiertas condenas a muerte ${ }^{65}$. Este cambio drástico de actitud estaría motivado por la muerte de Germánico y en adelante será muy severo con aquellos sobre los que ha caído la sospecha de haber conspirado contra él ${ }^{66}$.

\footnotetext{
${ }^{59}$ SUETONIO (1964) pp. 58-59 (de vita, 3.49.1).

${ }^{60}$ Suetonio (1964) p. 71 (de vita, 3.63). TÁcito (1965) p. 318 (An., 2.28) sostiene que las artes adivinatorias y los juegos de magia estaban por entonces prohibidos en Roma.

${ }^{61}$ SuEtonio (1964) p. 68 (de vita, 3.61.2).

${ }^{62}$ CASIO (1961) p. 240 (Hist, 58.22.1-2) indica que siempre le perseguirá la mala fama, incluso en el terreno sexual, al propagarse rumores en torno a su bisexualidad. CASIO (1961) p. 240 (Hist, 58.21.5-6) expone que la crueldad de Tiberio se hará patente por medio de la represión de Sejano y el resto de conspiradores; el emperador mandó matar a cuantos estuvieron en connivencia con él: el tiempo de los procesos había llegado a su fin y se imponía el capricho del emperador.

${ }^{63}$ CASIO (1961) p. 238 (Hist, 58.21.2).

${ }^{64}$ CASIO (1961) p. 182 (Hist, 57.24.7).

${ }^{65}$ CASIO (1961) p. 134 (Hist, 57.9.3).

${ }^{66}$ CASIO (1961) p. 164 (Hist, 57.19.1).
} 
No hay que pasar por alto el valor de los delatores en los procesos por maiestas, Tiberio se vale de ellos para enjuiciar a individuos que, por diferentes motivos, no eran de su agrado. Los delatores eran pagados con dinero del propio aerarium para favorecer su actividad incriminatoria. Otra iniciativa del emperador para promover los juicios por maiestas son las torturas $\mathrm{y}$, aunque los esclavos eran comprados para poder testificar contra sus ahora ex dominus, ciertos ciudadanos romanos son torturados en algunos procesos ${ }^{67}$, lo que demuestra claramente que se estaban pervirtiendo los cimientos más elementales del Derecho romano pues la legislación latina, en torno al 300 a.C., a través de la lex Porcia prohibía expresamente la tortura a ciudadanos romanos. Este escenario dramático favoreció los suicidios de los reus maiestatis antes de dictarse la previsible sentencia condenatoria, por ejemplo, Víbulo Agripa, en calidad de acusado se dio muerte en la propia curia ingiriendo veneno oculto en un anillo y cierto Nerva, en idéntica situación procesal, murió por inanición voluntaria ${ }^{68}$.

Conviene recordar las palabras de SUETONIO $^{69}$ denunciando la creciente persecución penal por actitudes calificadas como obscenas a la casa imperial, entre tales la introducción en prostíbulos de monedas grabadas con el rostro imperial, de hecho Tiberio ordenó ejecutar a un individuo que entró a un lupanar portando una moneda que tenía el rostro del emperador. En este clima de fuerte presión Tiberio llegó a redactar la instrucción de algunas causas, incluyendo las declaraciones de los testigos y los acusados, y con ello presionó al Senado para emitir condenas al dictado de su única voluntad ${ }^{70}$. En pocas palabras, Tiberio durante su gobierno manchó sus manos con sangre condenando sin la menor compasión a gran número de inocentes.

\section{CONCLUSIONES}

En los primeros tiempos de la historia de Roma la aplicación del Derecho tuvo un carácter privado. Los delitos contra la comunidad son el primer grupo de ilícitos calificados y enjuiciados por el poder público. El tipo penal nace para proteger la seguridad del naciente Estado romano, pero se pervierte su aplicación en diferentes momentos porque se emplea como arma política. El crimen evoluciona al delito de maiestas en el s. II a.C. priorizándose reprimir los diferentes atentados sobre los intereses del pueblo romano siendo ampliados los supuestos delictivos en tal sentido. El advenimiento del Principado también genera convulsión en este delito porque pasa a blindar la figura del emperador en tanto se entiende que él es la personificación última del Estado romano y, por ello, sobre quien atente en adelante, en la manera que fuese, contra el césar o la propia Institución, cae la acusación de un delito de maiestas y es Tiberio, como segundo emperador de Roma, quien inició este cambio, primero en forma ambigua, centrando la protección en su predecesor Augusto, para luego pasar abiertamente a proteger su misma persona. De este modo los relatos estudiados de Tácito, Suetonio y Casio transmiten esa voluntad de cambio, si bien mostrando un fondo de perversión como agente dinamizador.

\footnotetext{
${ }^{67}$ CASIO (1961) p. 166 (Hist, 57.19.2).

${ }^{68}$ CASIO (1961) pp. 238-239 (Hist, 58.21.4).

${ }^{69}$ SUETONiO (1964) p. 65 (de vita, 3.58).

${ }^{70}$ CASIO (1961) p. 238 (Hist, 58.21.3).
} 


\section{BIBLIOGRAFÍA CITADA}

BAUMAN, Richard Alexander (1970): The Crimen Maiestatis in the Roman Republic and Augustan Principate (Johannesburg, Witwatersrand University Press).

BlÁzQuez MARTíneZ, José María (2004): “Tiberio Emperador”. Disponible en: http://www.cervantesvirtual.com/obra/tiberio-emperador-0/, fecha de consulta: 10 de octubre de 2019.

CANTARElla, Eva (1996): Los suplicios capitales en Grecia y Roma (Trad. Marie-Pierre Bouysspon Cheval, Madrid, Akal).

CASIO (1961): Dio's Roman History. Vol. 9, Lib., LVI-LX (Harvard, University of Harvard).

CiCERÓN (1892): De Oratore (Oxford, Clarendon).

De CAStro-CAmero, Rosa María (2002): El crimen maiestatis a la luz del senatus consultum de Cn. Pisone Patre (Sevilla, Universidad de Sevilla).

KunKeL, Wolfgang (2012): Historia del Derecho romano (Trad. Joan Miquel González, Barcelona, Ariel).

LE Gall, Jöel y Le Glay, Marcel (1987): El Imperio romano. Tomo I: El Alto Imperio desde la batalla de Actium (31 a.C. hasta el asesinato de Severo Alejandro (235 d.C.) (Madrid, Akal).

LóPez Barja, Pedro y Lomas Salmonte, Francisco Javier (2004): Historia de Roma (Madrid, Akal).

MAs, Salvador (2011): "De Tácito a la lex de imperio Vespasiani o la organización del consentimiento de la dominación”, Sémata, vol. 23, pp.77-96

Mommsen, Theodor (1991): Derecho Penal romano (Bogotá, Témis).

PAVÓN TORREJÓN, Pilar (2003): La cárcel y el encarcelamiento en el mundo romano (Madrid, CSIC).

PINNA PolO, Francisco (1998): "De la República al Principado: claves políticas de la crisis de la res publica romana", Bilarte, vol. 15, pp. 113-131.

Ribas Alba, José María y Serrano ViCente, Martín (2012): El Derecho en Roma (Granada, Comares).

Roldán Hervás, José Manuel (2008): Césares: Julio César, Augusto, Tiberio, Calígula, Claudio y Nerón. La primera dinastía de la Roma imperial (Madrid, Esfera). 
SÁnCHEZ LEÓn, María Luisa (1998): El Alto Imperio Romano (Madrid, Síntesis).

SANTAlucia, Bernardo (1990): Derecho Penal romano (Trad. Javier Paricio Serrano, Madrid, Centro de Estudios Ramón Areces).

SbricCOLI, Mario (1974): Crimen Laesae Maiestatis. Il problema del relato político alle soglie della scienza penalistica moderna (Milán, Giuffrè Editore).

SHOTTER, David (2002): Tiberio (Madrid, Acento).

Suetonio (1964): Vida de los Doce Césares (Barcelona, Alma Mater).

TÁcito (1965): P. Cornelii Taciti. Annalium ab Excessu Diui Augusti Libri. Vol. I. Lib. IIV ( $2^{\mathrm{a}}$ ed., Oxford, University of Oxford).

TUORI, Kaius (2016): The Emperor of Law: The Emergence of Roman Imperial Adjudication (Nueva York, Oxford University Press). 